\title{
Body adiposity index a better marker of body fat than body mass index in wheelchair rugby players after cervical spinal cord injury (CSCI) - preliminary investigations
}

\author{
A. Zwierzchowska ${ }^{1 *}$, M. Glowacz ${ }^{1}$, A. Maszczyk ${ }^{2}$ and A. Zając ${ }^{2}$ \\ ${ }^{1}$ Department of Special Physical Education. The Jerzy Kukuczka Academy of Physical Education, Katowice, Poland \\ ${ }^{2}$ Department of Sports Theory. The Jerzy Kukuczka Academy of Physical Education, Katowice, Poland
}

\begin{abstract}
Objective: CSCI-related dysfunction frequently determines and generates other deficits and disorders. The aim of this study was to assess the accuracy of BAI, when compared to BMI in wheelchair rugby players after cervical spinal cord injury.

Methods: The study group consisted of 14 Caucasian males competing in wheelchair rugby players, aged 25-40 years (32.6 \pm 5.1 years), who had sustained CSCI. All subjects were measured for body height, waist and hip circumference in centimeters, while body mass was expressed in kilograms. Body fat content was measured with the use of Viscan Tanita AB-140 utilize BIA. The existence of significant bivariate correlations among variables such as BAI, BMI, height, weight, hip circumference and \% visceral fat and trunk fat determined by BIA was ascertained by means of determining Pearson correlation coefficients.

Results: BMI calculated according to the standards of the general population indicated that $80 \%$ of participants fell within the norm (BMI $<25)$, while according to BAI standards it was $40 \%$. After classifying the participants by the cut-off points of BMI $>25 \mathrm{~kg} / \mathrm{m}^{2}$ and BAI $>21 \%$, significant relationships were observed between BAI and the following indicators WC ( $\mathrm{r}=0.9), \% \mathrm{TF}(\mathrm{r}=0.9), \% \mathrm{VF}(\mathrm{r}=0.8)$, WHR ( $\mathrm{r}=0.8)$. Such a trend was not observed for BMI.
\end{abstract}

Conclusions: The BAI can be considered a good tool for evaluating adiposity in patients with spinal cord injury. BAI is very specific and sensitive.

\section{Introduction}

Disabled adults are more likely to become obese than their healthy counterparts [1]. Two studies of US veterans found that two-thirds of subjects with spinal cord injury (SCI) were overweight or obese by the BMI criteria [2,3]. CSCI-related dysfunction frequently determines and generates other deficits and disorders. Compensatory processes may lead to the development of cardiovascular diseases, the leading cause of death among patients with SCI. Current data indicates that the highest mortality rates have been registered following CSCI [4-6]. Enforced sedentary lifestyle and muscle paresis below the level of injury is associated with adipose tissue accumulation in the trunk. Visceral fat accumulation, in turn, favors the development of cardiac and metabolic diseases [7]. Post-traumatic complications affect almost all body systems and have the potential to worsen the patient's condition and accelerate the progression of disease. Research indicates that high levels of visceral fat (VF) and trunk fat (TF) are closely correlated to the incidence of lifestyle-related diseases [8].

Several studies have indicated an association between insulin resistance, abnormal lipid metabolism and visceral fat accumulation $[9,10]$. It has also been estimated that 1 in 13 annual deaths of European Union citizens is related to excess body weight [11] and cardiac disease [12]. A sedentary life style has been detrimentally associated with coronary heart disease (CHD) risk independently of moderate to vigorous physical activity (MVPA). However, it is unclear how the forced sedentary lifestyle of active athletes following spinal cord injury may influence such associations.
Recent studies have revealed that one of the anthropometric obesity indicators, i.e., BMI, has a low sensitivity in identifying populations at risk for $\mathrm{CHD}$ and cardiometabolic disease. Thus, it seems necessary to seek specific tools for the assessment of body composition and potential health risks in SCI patients. Numerous studies have evaluated the reliability and variability of various anthropometric indices assessing obesity and predicting obesity-related health risks, including body mass index (BMI), waist-to-hip ratio (WHR), waist circumference (WC), and waist-to-height ratio (WHtR) [13-15]. The primary means to assess obesity in population studies is the use of BMI with the standards recommended by the WHO. According to these standards overweight is defined as BMI greater than $25 \mathrm{~kg} / \mathrm{m}^{2}$ and obesity as BMI higher than $30 \mathrm{~kg} / \mathrm{m}^{2}[16,17]$. BMI is particularly inaccurate in subjects with elevated lean body mass, especially strength and power oriented athletes and cannot be generalized among different ethnic groups. It is likely that individuals are often misdiagnosed as having inappropriate body fat due to variation in muscle mass, and that certain subjects with significant adiposity are overlooked $[18,19]$. Lowering the body mass index cutoffs better identifies obese subjects with spinal cord injury.

Correspondence to: A. Zwierzchowska, Department of Special Physical Education. The Jerzy Kukuczka Academy of Physical Education, Katowice, Poland, Tel: (0-32) 207-51-33; E-mail: a.zwierzchowska@awf.katowice.pl

Key words: cervical spinal cord injury, BMI, BAI, rugby players

Received: June 22, 2015; Accepted: August 05, 2015; Published: August 10, 2015 
Rajan et al. (2008) and Laughton et al. (2009) suggest that body mass index cut of points should be lowered to better identify obese individuals with spinal cord injury. They believe that subjects with chronic spinal cord injury and BMI values $>22 \mathrm{~kg} / \mathrm{m}^{2}$ should be considered as being at high risk for obesity and obesity-related chronic diseases [20,21]. However, there is no agreement as to which index should be applied universally for defining obesity. That is why BMI is known to be of limited accuracy, and its diagnostic value is different for males and females with similar body adiposity. To address this limitation Bergman et al. (2011) introduced an alternative index, the Body Adiposity Index (BAI) in samples of Mexican-American and African-American populations 14. BAI can be measured without weighing, what makes it useful in settings where measuring accurate body weight is difficult. BAI allows estimating adiposity and cardiovascular risk, what has been confirmed in recent studies [14,15,22-24].

The aim of this study was to compare several estimates of body fat content, i.e., BAI, BMI, waist-to-hip ratio (WHR) and waist and hip circumferences regarding their accuracy (specific and sensitive) in predicting the percentage body fat (PBF) with the results obtained using a Viscan visceral and trunk fat analyzer. An additional objective of our research was to determine the relationship between BAI, BMI and other adiposity indices such as WC and WHR as well as cardiovascular and metabolic risk factors. Furthermore, to analyze BAI and BMI regarding their capacity to discriminate between overweight and obesity in wheelchair rugby players after cervical spinal cord injury.

\section{Materials and methods}

\section{Subjects and Study Protocol}

The study group consisted of 14 Caucasian males competing in wheelchair rugby players, aged $25-40$ years $(32.6 \pm 5.1$ years $)$, who had sustained CSCI (Table 1). Mean training experience was $7 \pm 3.5$ years. All subjects practiced wheelchair rugby by exercise once a week for three hours. They had no indication of cardio metabolic problems, evaluated by interview. Measurements were conducted by a qualified physiotherapist to minimize inter-observer differences.

All subjects were measured for body height $(\mathrm{BH})$, waist (WC) and hip circumference (HC) in centimeters, while body mass (BM) was expressed in kilograms (MENSOR Chair of EC type P3 $150 \mathrm{~K}$ ). Body length was measured in the supine position, because of the significant spasticity of patients with cervical spine injury (foot dorsiflexion). It was measured to the nearest $\mathrm{mm}$ and the final result was an average of 3 measurements. WC $(\mathrm{cm})$ and $\mathrm{HC}(\mathrm{cm})$ were measured with an anthropometric tape over light clothing. Waist was measured at the minimum circumference between the iliac crest and the rib cage and hip girth at the maximum width over the greater trochanters.

Body fat content was measured with the use of Abdominal Fat Analyzer Viscan Tanita AB-140 utilizes BIA (bioelectrical impedance analysis Tanita AB-140 (Tanita Corporation, Tokyo, Japan). The Viscan apparatus, has similar accuracy as DXA (gold standard) [25].

Table 1. Participant characteristics.

\begin{tabular}{|l|c|}
\hline Variable & \\
\hline Age (years) & $32.6 \pm 5.1$ \\
\hline Age at time of injury & $20.1 \pm 3.6$ \\
\hline Years post injury & $12.5 \pm 5.7$ \\
\hline Completeness of injury & \\
\hline Complete & $11(79 \%)$ \\
\hline Incomplete & $3(21 \%)$ \\
\hline
\end{tabular}

The new method estimating abdominal fat by BIA represents a reliable tool for clinical evaluation of trunk fat [26].

This is a novel device for direct measurements of body fat of subjects who for various reasons cannot assume an upright posture. The study was performed according to a standard protocol of the manufacturer: VISCAN is specifically designed for a wide range of needs from large scale research projects to routine clinical practice. Convenient to work with disabled, critically ill and elderly patients, measurements are taken in under 30 seconds. Viscan is easy to set up and use - no training required, gives highly accurate and repeatable results with minimal or no personal contact. Before the measurements are taken the tested subject assumes a lying position for about 10 minutes prior to the evaluation. Hands are placed on the chest, and the area to be tested is exposed. In subjects with severe spasticity - the lower limbs are stabilized by the person performing the test. Measurements are non-invasive and last about 30 seconds. The test is performed after an overnight fast. This is the basis for calculating body composition by an algorithm which includes age, sex and body height $[26,27]$. The investigated variables determined by BIA include trunk, visceral and subcutaneous fat. The latter was also used to estimate body fat content. BMI was calculated by the formula: BMI=weight $(\mathrm{kg}) /$ height $\left(\mathrm{m}^{2}\right) 17$. The BAI was calculated using the equation suggested by Bergman and colleagues, BAI $=(($ hip circumference $) /($ height $) 1.5)-18)[14]$.

WHR was then calculated, which helps to identify individuals with abdominal fat accumulation. WHO recommends the use of waist circumference measurement because it correlates closely with BMI and WHR, and is an approximate index of intra-abdominal fat mass and total body fat. BMI standards, i.e., BMI $>25$, and BAI cut-off points for men 20-39 years old (BAI>21\%), were used to identify overweight and obese subjects $[14,17]$.

The study was approved by the local Bioethical Committee of the Academy of Physical Education in Katowice, Poland (KB/15/2013). All tested subjects gave their written consent for participation in the study; anthropometric measurements were taken in a separate room.

\section{Statistical analyses}

Statistical analyses were performed with STATA statistical software (release 7; StataCorp, College Station, TX). All the data were tested for their normal distribution.

Results are presented as means \pm SD for normally distributed data and as means with $95 \%$ accuracy. The analysis of variance ANOVA was used to evaluate differences in indexes and anthropometric characteristics for BAI and BMI between cut-off points for BMI $>25 \mathrm{~kg} /$ $\mathrm{m}^{2}$ and $\mathrm{BAI}>21 \%$ (Tables 2 and 3 ). The existence of significant bivariate correlations among parameters such as BAI, BMI, body height, weight, hip circumference, $\%$ visceral fat and trunk fat determined by BIA was ascertained by means of determining Pearson correlation coefficients.

\section{Results}

When evaluating body composition, the participants were classified according to the risk of obesity. The classification was consistent with the standards adopted byWHO (Table 4). BMI calculated according to the standards of the general population indicated that $80 \%$ of participants fell within the norm (BMI > 25), while according to BAI standards it was $40 \%$. Among all the cervical spinal cord injury study participants the value recommended by $\mathrm{WHO}$ was exceeded (WHR= 0.9 or more).

The analysis of variance ANOVA revealed a significantly higher 
Zwierzchowska A (2015) Body adiposity index a better marker of body fat than body mass index in wheelchair rugby players after cervical spinal cord injury (CSCI) - preliminary investigations

Table 2. Comparison of wheelchair rugby players after CSCI by cut off points for BMI and BAI.

\begin{tabular}{|c|c|c|c|c|c|c|}
\hline \multirow[t]{2}{*}{ Components \& Indexes } & $\begin{array}{c}\text { BMI }<24.9 \\
\left(\mathrm{~kg} / \mathrm{m}^{2}\right)\end{array}$ & $\begin{array}{c}\text { BMI > } 25 \\
\left(\mathrm{~kg} / \mathrm{m}^{2}\right)\end{array}$ & \multirow[t]{2}{*}{ *P value } & $\begin{array}{c}\text { BAI }<20.9 \\
(\%)\end{array}$ & $\begin{array}{c}\text { BAI > } 21 \\
(\%)\end{array}$ & \multirow[t]{2}{*}{ *P value } \\
\hline & $\bar{x}$ for $n=11$ & $\bar{x}$ for $n=3$ & & $\bar{x}$ for $n=6$ & $\bar{x}$ for $n=8$ & \\
\hline $\mathrm{BM}[\mathrm{kg}]$ & $71.7 \pm 9.8$ & $86 \pm 1.7$ & $0.01^{*}$ & $77.2 \pm 7.8$ & $73 \pm 12.5$ & 0.5 \\
\hline $\mathrm{BH}[\mathrm{cm}]$ & $181.2 \pm 8.7$ & $178.0 \pm 2.6$ & 0.3 & $182.8 \pm 10.6$ & $178 \pm 4.9$ & 0.4 \\
\hline $\mathrm{WC}[\mathrm{cm}]$ & $89.6 \pm 6.6$ & $101.7 \pm 6.5$ & 0.06 & $92.2 \pm 5.0$ & $92.3 \pm 10.2$ & 0.9 \\
\hline $\mathrm{HC}[\mathrm{cm}]$ & $93.7 \pm 6.8$ & $100.3 \pm 8.9$ & 0.3 & $90.3 \pm 7.4$ & $98.8 \pm 5.4$ & $0.05^{*}$ \\
\hline TF [\%] & $27.9 \pm 5.6$ & $35.6 \pm 9.9$ & 0.3 & $30.1 \pm 5.3$ & $29.1 \pm 8.5$ & 0.8 \\
\hline VF [\%] & $12.0 \pm 3.6$ & $18.7 \pm 5.8$ & 0.2 & $13.4 \pm 4.0$ & $13.5 \pm 5.6$ & 0.9 \\
\hline WHR [cm] & $0.95 \pm 0.07$ & $1.01 \pm 0.04$ & 0.1 & $1.02 \pm 0.05$ & $1.04 \pm 0.9$ & $0.01^{*}$ \\
\hline
\end{tabular}

*statistical significance $\mathrm{p}<0.05 ; \mathrm{BM}[\mathrm{kg}]$ - body mass, $\mathrm{BH}[\mathrm{cm}]$-body height, $\mathrm{WC}[\mathrm{cm}]$ - waist circumference, $\mathrm{HC}[\mathrm{cm}]$ - hip circumference, TF[\%]- trunk fat percentage, $\mathrm{VF}[\%]-$ visceral fat percentage; WHR [\%]- waist-to-hip ratio;

Table 3. The correlations of cut of points for BMI or BAI - mean values and standard deviations $( \pm \mathrm{SD})$ of the studied anthropometric variables of wheelchair rugby players after CSCI.

\begin{tabular}{|c|c|c|c|c|c|c|c|}
\hline \multirow{2}{*}{$\begin{array}{l}\text { Components and } \\
\text { Indexes }\end{array}$} & \multirow{2}{*}{$\begin{array}{c}\text { Mean } \pm \text { SD } \\
n=14\end{array}$} & \multicolumn{3}{|c|}{ BMI $\left[\mathrm{kg} / \mathrm{m}^{2}\right]$} & \multicolumn{3}{|c|}{ BAI [\%] } \\
\hline & & $<24.9 \mathrm{n}=11$ & $\begin{array}{l}>25 \\
n=3\end{array}$ & $\begin{array}{c}\text { All } \\
n=14\end{array}$ & $\begin{array}{c}<20.9 \\
n=6\end{array}$ & $\begin{array}{l}>21 \\
\mathrm{n}=8\end{array}$ & $\underset{n=14}{\text { All }}$ \\
\hline $\mathrm{BM}[\mathrm{kg}]$ & $74.8 \pm 10.6$ & 0.7 & 0.3 & 0.8 & 0.1 & 0.7 & 0.2 \\
\hline $\mathrm{BH}[\mathrm{cm}]$ & $180.5 \pm 7.8$ & -0.05 & -0.8 & -0.2 & -0.4 & -0.3 & -0.5 \\
\hline $\mathrm{WC}[\mathrm{cm}]$ & $92.21 \pm 8.1$ & 0.7 & 0.8 & 0.8 & 0.02 & 0.9 & 0.4 \\
\hline $\mathrm{HC}[\mathrm{cm}]$ & $95.1 \pm 7.5$ & 0.1 & 0.97 & 0.4 & 0.4 & 0.7 & 0.7 \\
\hline $\mathrm{TF}[\%]$ & $29.5 \pm 7.1$ & 0.4 & 0.8 & 0.6 & -0.5 & 0.9 & 0.3 \\
\hline VF [\%] & $13.5 \pm 4.8$ & 0.3 & 0.6 & 0.6 & -0.7 & 0.8 & 0.2 \\
\hline WHR [cm] & $0.97 \pm 0.07$ & 0.5 & -0.9 & 0.5 & -0.7 & 0.8 & -0.3 \\
\hline BMI $\left[\mathrm{kg} / \mathrm{m}^{2}\right]$ & $22.9 \pm 3.0$ & 1 & 1 & 1 & 0.6 & 0.8 & 0.5 \\
\hline BAI [\%] & $21.3 \pm 3.3$ & 0.2 & 0.9 & 0.5 & 1 & 1 & 1 \\
\hline
\end{tabular}

*statistically significant $\mathrm{p}<0.05 ; \mathrm{BM}[\mathrm{kg}]$ - body mass, $\mathrm{BH}[\mathrm{cm}]$-body height, $\mathrm{WC}[\mathrm{cm}]$ - waist circumference, $\mathrm{HC}[\mathrm{cm}]$ - hip circumference, TF[\%]- trunk fat percentage, $\mathrm{VF}[\%]-$ visceral fat percentage; WHR[\%]- waist-to-hip ratio; BMI $[\mathrm{kg} / \mathrm{m}]^{2}$ - body mass index; BAI[\%]- body adiposity index

effect of BMI cut points in the $\mathrm{BM}\left(\mathrm{F}=12.321 ; \eta^{2}=0.644\right)$, and of BAI cut points in the $\mathrm{HC}\left(\mathrm{F}=9.142 ; \eta^{2}=0.501\right)$ and $\mathrm{WHR}\left(\mathrm{F}=14.065 ; \eta^{2}=0.726\right)$, (Table 2), values.

To select an optimal surrogate for adiposity, we examined the correlation between body adiposity percentage as measured by Viscan Tanita AB-140 which utilizes BIA and several variables, including BAI, BMI BM, BV, WC, HC and WHR. A significant outcome of verification rates in all groups, included higher correlation coefficients between $\mathrm{BMI}$ and $\% \mathrm{VF} r=0.6 ; \% \mathrm{TF} r=0.6$ than $\mathrm{BAI}$ and $\% \mathrm{VF} r=0.2 ; \% \mathrm{TF} r=0.3$ $\mathrm{P}<0.05$. However, after classifying the participants by the cut-off points of BMI $>25 \mathrm{~kg} / \mathrm{m}^{2}$ and $\mathrm{BAI}>21 \%$, significant relationships were observed between BAI and the following indicators: WC $r=0.9 ; \% \mathrm{TF}$ $\mathrm{r}=0.9 ; \% \mathrm{VF} r=0.8$; WHR $\mathrm{r}=0.8$. At the same time we observed low and inverse correlations in the group with $\mathrm{BAI}<20.9$. Such a trend was not observed for BMI (Table 3).

\section{Discussion}

Increased fat mass and coronary heart disease include secondary complications of chronic spinal cord injury. In the able-bodied population BMI is a widely used marker of obesity and predictor of CHD risk. Waist circumference is an accurate and reproducible measure of abdominal visceral fat, and is also associated with the risk of CHD (more than BMI) in the disabled population [28]. BAI measure was approved in the "triglycerides and cardiovascular risk in AfricanAmerican population study. The relationship between fat content evaluated by DXA and obesity classified with BAI was very high and equaled $\mathrm{r}=0.85$ [14,22-24]. Our study confirms significant relationships between $\mathrm{BAI}$ and $\% \mathrm{TF} \mathrm{r}=0.9 ; \% \mathrm{VF} \mathrm{r}=0.8$, especially when considering obese and overweight subjects with BAI $>21 \%$. At the same time there was a moderate and an inverse correlation in the group with BAI < $20.9 \% \mathrm{TF} r=(-0.5)$ and \%VF $r=(-0.7)$. Such a trend was not observed for BMI (Table 3).

BAI can be measured without weighting, which can make it useful in conditions in which an accurate measurement of body mass is problematic, for example in patients with spinal cord injury. It can be easily computed without the need of sophisticated equipment or specific software.

This study has several limitations which warrant further discussion. The first limitation is related to the small number of subjects evaluated in this research. Another limitation is the type of subjects considered, which included only wheelchair rugby players. It must be indicated that this a pilot study and for further research a greater number of subjects with CSCI (wheelchair rugby players and sedentary disabled males) must be evaluated to verify the sensitivity and specificity of BAI as a tool for measuring body fat content. This pilot study leads to the conclusion that BAI could be a good tool for evaluating adiposity, especially in disabled subjects, such as those with spinal cord injury. However numerous scientists indicate that BAI still needs to be tested among different ethnic groups and in disabled subjects [14,22-24,29]. Our results correspond with those of Suchanek et al. 2012 [30]. We can state that the BAI index is not universally valid, can't be used as a replacement of the BMI index in subjects after cervical spinal cord injury, since it does not accurately reflect body fat mass, what may lead to an increased risk of obesity. BAI identified $60 \%(n=8)$ of obese and 
Zwierzchowska A (2015) Body adiposity index a better marker of body fat than body mass index in wheelchair rugby players after cervical spinal cord injury (CSCI) - preliminary investigations

Table 4. Classification of wheelchair rugby players after CSCI according to population norm for somatic variables.

\begin{tabular}{|c|c|c|c|c|c|c|c|c|c|c|}
\hline \multirow{2}{*}{ Cut of point } & \multicolumn{2}{|c|}{$\mathrm{WC}[\mathrm{cm}]$} & \multicolumn{2}{|c|}{ VF [\%] } & \multicolumn{2}{|c|}{ TF [\%] } & \multicolumn{2}{|c|}{ BMI $\left[\mathbf{k g} / \mathbf{m}^{2}\right]$} & \multicolumn{2}{|c|}{ BAI [\%] } \\
\hline & $<90$ & $>90$ & $<13$ & $>13$ & $<30$ & $>\mathbf{3 0}$ & $<24.9$ & $>25$ & $<20.9$ & $>21$ \\
\hline $\mathrm{N}$ & 7 & 7 & 6 & 8 & 5 & 9 & 11 & 3 & 6 & 8 \\
\hline Mean & 85,7 & 98,7 & 10,4 & 17,5 & 25,1 & 37,5 & 21.8 & 27.2 & 18.6 & 23.4 \\
\hline SD & $\pm 4,1$ & $\pm 5,2$ & $\pm 1,8$ & $\pm 4,7$ & $\pm 3,1$ & $\pm 4,6$ & \pm 2.3 & \pm 0.8 & \pm 2.4 & \pm 2.4 \\
\hline p value * & \multicolumn{2}{|c|}{$0,01^{*}$} & \multicolumn{2}{|c|}{$0,01^{*}$} & \multicolumn{2}{|c|}{$0,002 *$} & \multicolumn{2}{|c|}{$0.001 *$} & \multicolumn{2}{|c|}{$0.001 *$} \\
\hline
\end{tabular}

*statistical significance $\mathrm{p}<0.05 ; \% \mathrm{WC}[\mathrm{cm}]$ - waist circumference, TF[\%]- trunk fat percentage, VF[\%]- visceral fat percentage; BMI $[\mathrm{kg} / \mathrm{m}]^{2}$ - body mass index; BAI $[\%]-$ body adiposity index

overweight subjects in our pilot study, where obesity was defined by waist circumference $>90 \mathrm{~cm}(50 \% ; n=7)$ and compared to BMI only $20 \%(n=3)$ (Table 4). The results of BAI and WC were similar for the Viscan BIA method evaluations. The WC method is known for low accuracy but is still recommended for subjects after cervical spinal cord injury. Considering that BIA Viscan is a method know for high accuracy, it seems a reliable tool for clinical evaluation of trunk fat [26]. Considering the results of our study we may recommend BAI for identifying obesity in subject after CSCI as a more sensitive and specific method than BMI.

\section{Conclusion}

The BAI can be considered a good tool for evaluating adiposity in patients with spinal cord injury. The most important advantage of BAI over BMI is that precise measurements of body weight are not necessary. The fact that a high, statistically significant correlation between BAI and $\% \mathrm{VF}(\mathrm{r}=0.8)$ was registered among obese and overweight subjects as well as a moderate and inverse correlation between BAI $<20.9 \%$ and $\% \mathrm{VF}(\mathrm{r}=-0.7)$ in comparison to all $(\mathrm{r}=0.2)$ the subjects with CSCI suggests, that BAI is a very specific and sensitive index. The adiposity indexes that include waist circumference (WC, BAI) may be better candidates than BMI to evaluate metabolic and cardiovascular risks in clinical practice and research for patients with spinal cord injury. Furthermore, the WHR index is not suitable for estimation of body fat in wheelchair rugby players after CSCI.

\section{References}

1. Weil E, Wachterman M, McCarthy EP, Davis RB, O'Day B, et al. (2002) Obesity among adults with disabling conditions. JAMA 288: 1265-1268. [Crossref]

2. Gater DR Jr (2007) Obesity after spinal cord injury. Phys Med Rehabil Clin N Am 18: 333-351, vii. [Crossref]

3. Gupta N, White KT, Sandford PR (2006) Body mass index in spinal cord injury - a retrospective study. Spinal Cord 44: 92-94. [Crossref]

4. Frankel HL, Coll JR, Charlifue SW, Whiteneck GG, Gardner BP, et al. (1998) Longterm survival in spinal cord injury: a fifty year investigation. Spinal Cord 36: 266-274. [Crossref]

5. DeVivo MJ, Krause JS, Lammertse DP (1999) Recent trends in mortality and causes of death among persons with spinal cord injury. Arch Phys Med Rehabil 80: 1411-1419. [Crossref]

6. Garshick E, Kelley A, Cohen SA, Garrison A, Tun CG, et al. (2005) A prospective assessment of mortality in chronic spinal cord injury. Spinal Cord 43: 408-416. [Crossref]

7. Maruyama Y, Mizuguchi M, Yaginuma T, Kusaka M, Yoshida H, et al. (2008) Serum leptin, abdominal obesity and the metabolic syndrome in individuals with chronic spinal cord injury. Spinal Cord 46: 494-499. [Crossref]

8. Ford ES, Croft JB, Posner SF, Goodman RA, Giles WH (2013) Co-occurrence of leading lifestyle-related chronic conditions among adults in the United States, 20022009. Prev Chronic Dis 10: E60. [Crossref]
9. Marcus MA, Murphy L, Pi-Sunyer FX, Albu JB (1999) Insulin sensitivity and serum triglyceride level in obese white and black women: relationship to visceral and truncal subcutaneous fat. Metabolism 48: 194-199. [Crossref]

10. Reis JP, Macera CA, Araneta MR, Lindsay SP, Marshall SJ, et al. (2009) Comparison of overall obesity and body fat distribution in predicting risk of mortality. Obesity (Silver Spring) 17: 1232-1239. [Crossref]

11. Gutin B, Islam S, Manos T, Cucuzzo N, Smith C, et al. (1994) Relation of percentage of body fat and maximal aerobic capacity to risk factors for atherosclerosis and diabetes in black and white seven- to eleven-year-old children. J Pediatr 125: 847-852. [Crossref]

12. Leiter LA, Abbott D, Campbell NR, Mendelson R, Ogilvie RI, (1999) Lifestyle modifications to prevent and control hypertension. 2. Recommendations on obesity and weight loss. Canadian Hypertension Society, Canadian Coalition for High Blood Pressure Prevention and Control, Laboratory Centre for Disease Control at Health Canada, Heart and Stroke Foundation of Canada. CMAJ 160: 7-12.

13. Taylor RW, Keil D, Gold EJ, Williams SM, Goulding A (1998) Body mass index, waist girth, and waist-to-hip ratio as indexes of total and regional adiposity in women evaluation using receiver operating characteristic curves. Am J Clin Nutr 67: 44-49. [Crossref]

14. Bergman RN, Stefanovski D, Buchanan TA, Sumner AE, Reynolds JC, et al. (2011) A better index of body adiposity. Obesity (Silver Spring) 19: 1083-1089. [Crossref]

15. Barreira TV, Harrington DM, Staiano AE, Heymsfield SB, Katzmarzyk PT (2011) Body adiposity index, body mass index, and body fat in white and black adults. JAMA 306: 828-830. [Crossref]

16. Chan RS, Woo J (2010) Prevention of overweight and obesity: how effective is the current public health approach. Int J Environ Res Public Health 7: 765-783. [Crossref]

17. [No authors listed] (2000) Obesity: preventing and managing the global epidemic. Report of a WHO consultation. World Health Organ Tech Rep Ser 894: i-xii, 1-253. [Crossref]

18. Bouchard C (2007) BMI, fat mass, abdominal adiposity and visceral fat: where is the 'beef'? Int J Obes (Lond) 31: 1552-1553. [Crossref]

19. Taylor RW, Keil D, Gold EJ, Williams SM, Goulding A (1998) Body mass index, waist girth, and waist-to-hip ratio as indexes of total and regional adiposity in women: evaluation using receiver operating characteristic curves. Am J Clin Nutr 67: 44-49. [Crossref]

20. Rajan S, McNeely MJ, Warms C, Goldstein B (2008) Clinical assessment and management of obesity in individuals with spinal cord injury: a review. J Spinal Cord Med 31: 361-372. [Crossref]

21. Laughton GE, Buchholz AC, Martin Ginis KA, Goy RE; SHAPE SCI Research Group (2009) Lowering body mass index cutoffs better identifies obese persons with spinal cord injury. Spinal Cord 47: 757-762. [Crossref]

22. Elisha B, Rabasa-Lhoret R, Messier V, Abdulnour J, Karelis AD (2013) Relationship between the body adiposity index and cardiometabolic risk factors in obese postmenopausal women. Eur J Nutr 52: 145-151. [Crossref]

23. Kaushik B (2011) Is body adiposity index a good measure of nutritional status? A study among two adult tribal populations of Paschim Medinipur, West Bengal, India. Science Journal of Sociology and Anthropology : 1-4

24. López AA, Cespedes ML, Vicente T, Tomas M, Bennasar-Veny M, et al. (2012) Body adiposity index utilization in a Spanish Mediterranean population: comparison with the body mass index. PLoS One 7: e35281. [Crossref]

25. Shuster A, Patlas M, Pinthus JH, Mourtzakis M (2012) The clinical importance of 
Zwierzchowska A (2015) Body adiposity index a better marker of body fat than body mass index in wheelchair rugby players after cervical spinal cord injury (CSCI) - preliminary investigations

visceral adiposity: a critical review of methods for visceral adipose tissue analysis. $\mathrm{Br}$ J Radiol 85: 1-10. [Crossref]

26. Zamrazilová H, Hlavatý $\mathrm{P}$, Dušátková L, Sedlácková $\mathrm{B}$, Aldhoon Hainerová $\mathrm{I}$, et al (2010) A new simple method for estimating trunk and visceral fat by bioelectrical impedance: Comparison with magnetic resonance imaging and dual X-ray absorptiometry in Czech adolescents. Casopis Lekaru Ceskych 149: 417-422.

27. Kyle UG, Bosaeus I, De Lorenzo AD, Deurenberg P, Elia M, et al. (2004) Bioelectrica impedance analysis-part II: utilization in clinical practice. Clin Nutr 23: 1430-1453. [Crossref]
28. Buchholz AC, Bugaresti JM (2005) A review of body mass index and waist circumference as markers of obesity and coronary heart disease risk in persons with chronic spinal cord injury. Spinal Cord 43: 513-518. [Crossref]

29. Zwierzchowska A, Grabara M, Palica D, ZajÄ...c A (2013) BMI and BAI as markers of obesity in a Caucasian population. Obes Facts 6: 507-511. [Crossref]

30. Suchanek P, Kralova Lesna I, Mengerova O, Mrazkova J, Lanska V, et al. (2012) Which index best correlates with body fat mass: BAI, BMI, waist or WHR? Neuro Endocrinol Lett 33 Suppl 2: 78-82. [Crossref]

Copyright: C2015 Zwierzchowska A. This is an open-access article distributed under the terms of the Creative Commons Attribution License, which permits unrestricted use, distribution, and reproduction in any medium, provided the original author and source are credited. 